\title{
Composição centesimal e teor de colesterol do camarão branco do Pacífico
}

\author{
Proximate composition and cholesterol content of the Pacific white shrimp
}

\author{
Daline Fernandes de Souza Araujo ${ }^{\mathrm{I}}$ Danielle Damasceno Silvestre $^{\mathrm{I}}$ \\ Karla Suzanne Florentino da Silva Chaves Damasceno ${ }^{\mathrm{I}}$ Lucia de Fátima Campos Pedrosa ${ }^{\mathrm{I}}$ \\ Larissa Mont’ Alverne Jucá Seabra ${ }^{\mathrm{I}}$
}

\begin{abstract}
O objetivo deste estudo foi determinar a composição centesimal e o teor de colesterol da carne do camarão branco do Pacífico (Litopenaeus vannamei), oriundo de uma fazenda localizada no estado do Rio Grande do Norte, Brasil. As análises na porção muscular do camarão foram realizadas após a retirada do cefalotórax e exoesqueleto. De acordo com os resultados obtidos, os teores de umidade, proteínas, cinzas, lipídios e colesterol apresentaram valores médios de 74,1g $100 \mathrm{~g}^{-1}$, 21,9g $100 \mathrm{~g}^{-1}$, 1,5g $100 \mathrm{~g}^{-1}$, $0,3 \mathrm{~g} 100 \mathrm{~g}^{-1} \mathrm{e}$ $26,1 \mathrm{mg} 100 \mathrm{~g}^{-1}$, respectivamente. Comparando-se os resultados da presente pesquisa com os encontrados na literatura para outras espécies, observou-se que a carne de L. vannamei apresentou baixo teor de lipídeos e colesterol e maiores concentrações de proteínas, representando grande valor nutricional para o produto.
\end{abstract}

Palavras-chave: camarão, Litopenaeus vannamei, proteínas, lipídios, colesterol.

\section{ABSTRACT}

This study aimed to determine the proximate composition and cholesterol content in muscular portion of Pacific white shrimp (Litopenaeus vannamei) collected from a shrimp farm located in the state of Rio Grande do Norte, Brazil. The analysis in the muscular portion were performed after cephalothorax and exoskeleton removal. According to the results, the moisture, protein, ash, lipids and cholesterol had

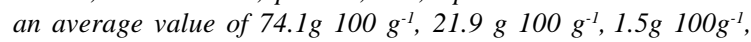

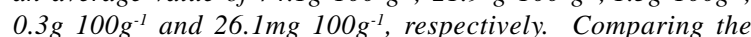
results found on this research to data reported in the literature for other species, it can be observed that the flesh of the shrimp
L. vannamei showed a low content of lipids and cholesterol and higher concentrations of protein, representing a wide nutritional value to the product.

Key words: shrimp, Litopenaeus vannamei, proteins, lipids, cholesterol.

Produtos marinhos têm atraído atenção considerável dos consumidores pelo fato de representar importante fonte de nutrientes para a dieta humana. Os crustáceos são alimentos geralmente consumidos em regiões costeiras e apresentam um valor nutricional considerável. Dentre estes, destaca-se o camarão, que, em sua porção muscular, é composto de proteínas de boa qualidade, minerais e baixa quantidade de lipídios totais (SANTOS et al., 2007; PEDROSA \& COZZOLINO, 2001; SRIKET et al., 2007).

O conhecimento da composição dos alimentos é importante não só para os profissionais da área da saúde, mas para os consumidores, que demonstram cada vez mais interesse sobre alimentos que contribuem para uma dieta equilibrada (LOPÉZCERVANTES et al., 2006).

O colesterol pode ser facilmente encontrado em produtos de origem animal, principalmente aqueles que apresentam quantidade elevada de gordura, ou peles. Fontes de gordura como manteiga, banha de

'Departamento de Nutrição, Universidade Federal do Rio Grande do Norte (UFRN), Av. Gal. Gustavo Cordeiro de Farias, s/n, 59012-570, Petrópolis, Natal, RN, Brasil. E-mail: daline_araujo@yahoo.com.br. *Autor para correspondência. 
porco, gordura das carnes e frituras, uma vez ingeridas em excesso, por conterem grandes quantidades de gordura saturada e colesterol, podem elevar o colesterol sérico. Os níveis séricos de colesterol e outras frações lipídicas estão relacionados aos hábitos alimentares inadequados, fatores intrínsecos do organismo e outros fatores de risco para Doenças Cardiovasculares (LIMA et al., 2000; BAGGIO \& BRAGAGNOLO, 2004; TSAPE et al., 2010).

Embora existam na literatura dados referentes aos teores nutricionais de várias espécies de camarão, a composição da carne de camarão $\boldsymbol{L}$. vannamei, cultivado no Brasil, tem sido pouco explorada. Dessa forma, o presente trabalho tem por objetivo realizar a análise da composição centesimal, assim como determinar o teor de colesterol na carne do camarão.

As amostras procederam de 4 lotes ( $2 \mathrm{~kg}$ cada)de $\boldsymbol{L}$. vannamei de água salgada, cedidos por uma fazenda localizada no estado do Rio Grande do Norte. Elas foram transportadas sob congelamento até o Laboratório de Análise de Alimentos do Departamento de Nutrição da Universidade Federal do Rio Grande do Norte (UFRN).

As análises de umidade, cinzas, proteínas, lipídios totais e colesterol foram realizadas em triplicata na porção muscular (carne) do camarão. As amostras permaneceram armazenadas a $-31^{\circ} \mathrm{C}$ até o momento das análises. Para a realização das análises, as amostras foram descongeladas a $4^{\circ} \mathrm{C}$ e, em seguida, foi feito o beneficiamento para a retirada do cefalotórax e exoesqueleto.

Umidade, cinzas e proteínas foram determinadas por métodos analíticos preconizados pela AOAC (2000). Os lipídios totais foram extraídos pelo método de BLIGH \& DYER(1959), utilizando-se extração com clorofórmio:metanol:água (1:2:1). A determinação de colesterol foi realizada segundo BOHAC et al. (1988) adaptado por BRAGAGNOLO \& RODRIGUEZAMAYA (1995). As absorbâncias obtidas foram comparadas às da curva padrão utilizada segundo SEARCY \& BERGQUIST(1960).

Os resultados das análises físico-químicas das amostras de camarão foram avaliados de acordo com métodos de estatística descritiva, calculando-se os valores médios e desvio padrão para todas as variáveis.

Os valores médios da composição centesimal e de colesterol encontrados na carne do camarão foram: $74,1 \pm 0,6 \mathrm{~g} 100 \mathrm{~g}^{-1}$ de umidade; $1,5 \pm 0,1 \mathrm{~g}$ $100 \mathrm{~g}^{-1}$ de cinzas; $21,9 \pm 0,5 \mathrm{~g} 100 \mathrm{~g}^{-1}$ de proteínas; $0,3 \pm 0,1 \mathrm{~g}$

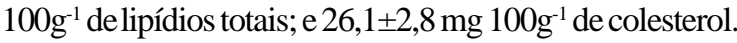

A umidade foi semelhante à encontrada por SANTOS et al. (2007) em camarões da Malásia, nos quais foram observados valores de umidade de 73,1 e 74,4\%. KIRSCHNIK \& VIEGAS (2004) encontraram na espécie Macrobrachium resenbergii umidade média de $78,5 \%$

No presente estudo, observou-se que o teor de cinzas na carne do camarão foi semelhante ao de Macrobrachium resenbergii (HEU et al., 2003; FURUYA, et al., 2006) e inferior ao relatado para o camarão rosa Penaeus brasiliensis, de 2,3 e 2,4\% (CADUN et al., 2005; CADUN et al., 2008).

A concentração de proteína observada neste estudo esteve acima dos valores referidos nas tabelas de composição de alimentos. Na tabela de composição de alimentos de PHILIPPI(2002), o valor de proteína é de $20,3 \%$ para a carne do camarão cru (espécie não referida). Já a tabela de composição de alimentos - TACO (2011) - apresenta valor inferior (10g\%) para o camarão cru de água salgada Penaeus brasiliensis. KIRSCHNIK \& VIEGAS (2004) encontraram 19,50g\% de proteína no camarão de água doce $\boldsymbol{M}$. rosenbergii e HEU et al. (2003) valores de $13,4 g \%$ e $14,9 g \%$ no músculo do camarão Pandalus borealis e Trachypena curvirostris, respectivamente.

O teor de lipídios totais do $\mathbf{L}$. vannamei foi semelhante ao encontrado no camarão Parapenaeus longirostrisi (0,35\%) e no P. borealis (0,40\%) (CADUN et al., 2005; HEU et al., 2003), porém os valores estão abaixo dos observados na carne do camarão Xiphopenaeus kroyeri, que variou de 0,5 e 1,1\%, e da espécie $\boldsymbol{P}$. longirostris, que apresentou 1,3\% de lipídios totais (KRZYNOWEK \& PANUNZIO, 1989; CADUN et al., 2008).

O valor médio de colesterol do camarão observado neste estudo foi inferior ao encontrado na literatura, quando comparado à mesma espécie e outras espécies de camarões. Para SANTOS et al. (2007), vários fatores determinam a composição química de uma determinada espécie, dentre eles, a alimentação, genética, sexo, estágio reprodutivo, tamanho e migração, além daqueles relacionados às variações ambientais e formas de criação.

O ambiente de cultivo, água doce e salgada também podem ter influência sobre os valores de colesterol, como relatado no estudo de MOURA (2004), no qual foram utilizados lotes de L. vannamei cultivado em água doce e água salobra e do Farfantepenaeus schimitti de água salgada. O teor de colesterol para o camarão cultivado em água doce variou de 47,74 a 69,32mg $100 \mathrm{~g}^{-1}$, sendo estes os que mais se aproximaram ao deste estudo, e valores mais elevados foram 
encontrados para camarão de água salgada com variação de $218,20 \mathrm{mg}^{100 \mathrm{~g}^{-1} \mathrm{a}} 361,17 \mathrm{mg} 100 \mathrm{~g}^{-1}$. Na carne de $\boldsymbol{P}$. brasiliensis, a concentração de colesterol foi de $127,0 \pm 9 \mathrm{mg}^{100 \mathrm{~g}^{-1}}$ (BRAGAGNOLO \& RODRIGUEZAMAYA, 1997). Em outro estudo, utilizando a mesma espécie, os mesmos autores encontraram valor inferior, 114,0mg $100 \mathrm{~g}^{-1}$, mas, para o gigante da Malásia, o colesterol foi mais elevado, apresentando valor de 139,0mg $100 \mathrm{~g}^{-1}$ (BRAGAGNOLO \& RODRIGUEZAMAYA, 2001).

Diante do exposto, a porção muscular do camarão marinho branco do Pacífico (L. vannamei) cultivado no Rio Grande do Norte apresentou teores de umidade e cinzas semelhantes aos relatados em outras espécies. Porém, as baixas concentrações de lipídios e colesterol, e teores significativos de proteína indicam excelente valor nutricional desta espécie de camarão.

\section{REFERÊNCIAS}

AOAC (Association of Official Analytical Chemistry). Official methods of analysis of the Association of Official Analytical Chemistry. 17.ed. Washington, 2000. 1170p.

BAGGIO, S.R.; BRAGAGNOLO, N. Validação da metodologia para determinação simultânea, por CLAE, de colesterol e óxidos de colesterol em produtos cárneos processados. Ciênc Tecnol Aliment, v.24, n.1, p.64-70, 2004. Disponível em: <http:// www.scielo.br/ scielo.php?script=sci_arttext\&pid=S010120612004000100013\&lng=en\&nrm=iso>. Acesso em: 20 jun. 2011. doi: 10.1590/S0101-20612004000100013.

BLIGH, E.G.; DYER, W.J. A rapid method of total lipid extraction and purification. Can J Biochem Physiol, v.37, n.8, p.911-917, 1959. Disponível em: <http:// www.nrcresearchpress. com/doi/abs/10.1139/o59-099>. Acesso em: 03 jul. 2011. doi: 10.1139/o59-099.

BOHAC, C.E. et al. Assessment of methodologies for colorimetric cholesterol assay of meats. J Food Sci, v.53, n.6, p.1642-1644, 1988. Disponível em: <http://onlinelibrary. wiley.com/doi/10.1111/j.1365-2621.1988.tb07804.x/abstract $>$. Acesso em: 03 jul. 2011. doi: 10.1111/j.13652621.1988.tb07804.x.

BRAGAGNOLO, N.; RODRIGUEZ-AMAYA, D. B. Teores de colesterol em carne suína e bovina e efeito do cozimento. Ciênc Tecnol Aliment, v.15, n.1, p.11-17, 1995. Disponível em: $<$ http://www.scielo.br/scielo.php?script=sci_arttext\&pid=S010120612002000100018\&l ng=en\&nrm=iso>. Acesso em: 20 ago. 2011. doi: 10.1590/S0101-20612002000100018.

BRAGAGNOLO, N.; RODRIGUEZ-AMAYA, D.B. Otimização da determinação de colesterol por CLAE e teores de colesterol, lipídios totais e ácidos graxos em camarão-rosa (Penaeus brasiliensis). Ciênc Tecnol Aliment, v.17, n.3, p. 275-280, 1997. Disponível em: <http://www.scielo.br/scielo.php?script=sci_arttext\&pid=S010120611997000300016\&lng=e n\&nrm=iso >. Acesso em: 20 ago. 2011. doi: 10.1590/S0101-20611997000300016.
BRAGAGNOLO, N.; RODRIGUEZ-AMAYA, D.B. Total lipid, cholesterol, and fatty acids of farmed freshwater prawn (Macrobrachium rosenbergii) and wild marine shrimp (Penaeus brasiliensis, Penaeus schimitti, Xiphopenaeus kroyeri). J Food Comp Anal, v.14, p.359-369, 2001. Disponível em: <http:// www.sciencedirect.com/science/article/pii/S08891575009 09815>. Acesso em: 25 ago. 2011. doi: 10.1016/ j.bbr.2011.03.031.

CADUN, A. et al. A study of marination of deep-water pink shrimp (Parapenaeus longirostris) and its shelf life. Food Chem, v.90, n.1/2, p.53-59, 2005. Disponível em: <http:// w w w. sciencedirect.com/s cience/article/pi i / S0308814604002651>. Acesso em: 03 de jul. 2011. doi: 10.1016/j.foodchem.2004.03.024.

CADUN, A. et al. Marination of deep-water shrimp with rosemary extract and the determination of its shelf life. Food Chem, v.109, n.1, p.81-87, 2008. Disponível em: <http:// w w w.sciencedirect.com/science/article/pi i / S0308814607012770>. Acesso em: 04 de jul. 2011. doi: 10.1016/j.foodchem.2007.12.021.

FURUYA, W.M. et al. Composição centesimal e perfil de ácidos graxos do camarão d’água doce. R Bras Zootec, v.35, n.4. p.1577-1580, 2006. Disponível em: <http://www.scielo.br/ s c i e l o.ph p ? s c ri p t = s c i_art text \& pi d = S 1516 35982006000600001\&lng=e n\&nrm=iso>. Acesso em: 07 ago. 2011. doi: 10.1590/S1516-35982006000600001.

HEU, M. et al. Components and nutritional quality of shrimp processing by-products. Food Chem, v.82, n.2, p.235-342, 2003. Disponível em: <http://www.sciencedirect.com/science / article/pii/S0308814602005198>. Acesso em: 20 ago. 2011. doi: 10.1016/S0308-8146 (02)00519-8.

KIRSCHNIK, P.G.; VIEGAS, E.M.M. Alterações na qualidade do camarão de água doce Macrobrachium rosenbergii durante estocagem em gelo. Ciênc Tecnol Aliment, v.24, n.3, p.407-412, 2004. Disponível em: <http://www.scielo.br/scielo.php?script=sci_artte xt\&pid=S0101-20612004000300019\&lng=en\&nrm=iso >. Acesso em: 25 ago. 2011. doi: 10.1590/S0101-20612004000300019.

KRZYNOWEK, J.; PANUNZIO, L.J. Cholesterol and fatty acids in several species of shrimp. J Food Sci, v.54, n.2, p.237-239, 1989. Disponível: < http://onlinelibrary.wiley.com/ doi/10.1111/j.1365-2621.1989.tb03051.x/pdf>. Acesso em: 07 ago. 2011. doi: 10.1111/j.1365 -2621.1989.tb03051.x

LIMA, F.E.L. et al. Ácidos graxos e doenças cardiovasculares: uma revisão. Rev Nutr, v.3, n.2, p.73-80, 2000. Disponível em: <http://www.scielo.br/scielo.php?script=sci_arttext\&pid= S1415-52732000000200001\&lng=en\&nrm=iso >. Acesso em: 07 ago. 2012. doi:10.1590/S1 415-52732000000200001.

LOPÉZ-CERVANTES, J. et al. High-performance liquid chromatography method for the simultaneous quantification of retinol, a-tocopherol, and cholesterol in shrimp waste hydrolysate. J Chromat, v.105, n.1, p.135-139, 2006. Disponível em: <http://www.science direct.com/science/article/ pii/S0021967305016341>. Acesso em: 25 ago. 2011. doi:10.1016/j.chroma.2005.08.010.

MOURA, L.B. Avaliação do rendimento de filé e da composição lipídica do camarão nativo (F. schimitti) e do cultivado (L. vannamei) em diferentes salinidades e pesos. 
2004. 55f. Dissertação (Mestrado em Ciência e Tecnologia de Alimentos) - Programa de Pós-graduação Ciência e Tecnologia de Alimentos, Universidade Federal da Paraíba, PB.

PEDROSA, L.F.C.; COZZOLINO, S.M. Composição centesimal e de minerais de mariscos crus e cozidos da cidade de Natal/ RN. Ciênc Tecnol Aliment, v.21, n.2, p.154-157, 2001. Disponível em: <http:/ /www.scielo.br/scielo.php?script=sci_arttext \&pid=S010120612001000200006\&lng=en\&nrm=iso>. Acesso em: 20 ago. 2011. doi: 10.1590/S0101-20612001000 200006.

PHILIPPI, S.T. Tabela de composição dos alimentos: suporte para decisão nutricional. 2.ed. Brasília: Editora Gráfica Coronário, 2002. 135p.

SANTOS, F.L. et al. Efeito do fornecimento de ração complementada com semente de linhaça sobre os macronutrientes e colesterol em tecidos de camarões da Malásia (Macrobrachium rosenbergii). Ciênc Tecnol Aliment, v.27, n.4, p.851-855, 2007. Disponível em: <http://www.scielo.br/ scielo.ph p ? s cript = s ci__art text \& pid = S 0101 20612007000400027\&ln g=en\&nrm=iso>. Acesso em: 07 ago. 2011. doi:10.1590/S0101-20612007000400027.
SEARCY, R.L.; BERGQUIST, L.M. A new color reaction for the quantitation of serum cholesterol. Clin Chim Acta, v.5, p.192-199, 1960. Disponível em: <http://www.sciencedire ct.com/science/article/pii/0009898160900358>. Acesso em: 20 jun. 2011. doi: 10.1016/0009-8981(60)90035-8.

SRIKET, P. et al. Comparative studies on chemical composition and thermal properties of black tiger shrimp (Penaeus monodon) and white shrimp (Penaeus vannamei) meats. Food Chem, v.103, n.4, p.1199-1207, 2007. Disponível em: <http:// www.sciencedirect.com/science/article/pii/S0308814606008107>. Acesso em: 04 jul. 2011. doi: 10.1016/j.foodchem .2006.10.039.

TACO. Tabela de Composição de Alimentos. 4.ed. rev. e ampl. Campinas: NEPA-UNICAMP, 2011. 161p.

TSAPE, K. et al. Comparative analysis of the fatty acid and sterol profiles of widely consumed Mediterranean crustacean species. Food Chem, v.122, p.292-299, 2010. Disponível em: <http://www.sciencedirect.com/science/article/pii/ S0308814610001834>. Acesso em: 20 jun. 2011. doi: 10.1016/ j.foodchem.2010.02.019.d 